(1)

CrossMark

\title{
Riociguat for the treatment of pulmonary arterial hypertension: a long-term extension study (PATENT-2)
}

\begin{abstract}
Lewis J. Rubin ${ }^{1}$, Nazzareno Galiè ${ }^{2}$, Friedrich Grimminger ${ }^{3,4}$, Ekkehard Grünig ${ }^{5}$, Marc Humbert ${ }^{6,7,8}$, Zhi-Cheng Jing ${ }^{9}$, Anne Keogh ${ }^{10}$, David Langleben ${ }^{11}$, Arno Fritsch ${ }^{12}$, Flavia Menezes ${ }^{13}$, Neil Davie ${ }^{12}$ and Hossein-Ardeschir Ghofrani $i^{3,4,14}$

Affiliations: 'Dept of Medicine, University of California, San Diego, La Jolla, California, USA. ${ }^{2}$ Dept of Experimental, Diagnostic and Specialty Medicine-DIMES, Bologna University Hospital, Bologna, Italy. ${ }^{3}$ University of Giessen and Marburg Lung Center (UGMLC), Giessen, Germany. ${ }^{4}$ Member of the German Center of Lung Research (DZL). ${ }^{5}$ Centre for Pulmonary Hypertension, Thoraxclinic, University Hospital Heidelberg, Heidelberg, Germany. ${ }^{6}$ Université Paris-Sud, Le Kremlin-Bicêtre, France. ${ }^{7}$ AP-HP Service de Pneumologie, DHU Thorax Innovation, Hôpital Bicêtre, Le Kremlin-Bicêtre, France. ${ }^{8}$ INSERM U999, LabEx LERMIT, Centre Chirurgical Marie Lannelongue, Le Plessis, Robinson, France. ${ }^{9}$ State Key Laboratory of Cardiovascular Disease, Fu Wai Hospital, Peking Union Medical College and Chinese Academy of Medical Sciences, Beijing, China. ${ }^{10}$ St Vincent's Hospital, Sydney, Australia. ${ }^{11}$ Center for Pulmonary Vascular Disease and Lady Davis Institute, Jewish General Hospital, McGill University, Montreal, Canada. ${ }^{12}$ Global Clinical Development, Bayer HealthCare Pharmaceuticals, Wuppertal, Germany. ${ }^{13}$ Bayer HealthCare Pharmaceuticals, São Paulo, Brazil. ${ }^{14}$ Dept of Medicine, Imperial College London, London, UK.
\end{abstract}

Correspondence: Lewis J. Rubin, University of California, San Diego, 5550 Caminito Genio, La Jolla, CA 92037, USA. E-mail: ljralewisrubinmd.com

ABSTRACT Riociguat is a soluble, guanylate cyclase stimulator, approved for pulmonary arterial hypertension. In the 12-week PATENT-1 study, riociguat was well tolerated and improved several clinically relevant end-points in patients with pulmonary arterial hypertension who were treatment naïve or had been pretreated with endothelin-receptor antagonists or prostanoids. The PATENT-2 open-label extension evaluated the long-term safety and efficacy of riociguat.

Eligible patients from the PATENT-1 study received riociguat individually adjusted up to a maximum dose of $2.5 \mathrm{mg}$ three times daily. The primary objective was to assess the safety and tolerability of riociguat; exploratory efficacy assessments included 6-min walking distance and World Health Organization (WHO) functional class.

Overall, 396 patients entered the PATENT-2 study and 324 (82\%) were ongoing at this interim analysis (March 2013). The safety profile of riociguat in PATENT-2 was similar to that observed in PATENT-1, with cases of haemoptysis and pulmonary haemorrhage also being observed in PATENT-2. Improvements in the patients', 6-min walking distance and WHO functional class observed in PATENT-1 persisted for up to 1 year in PATENT-2. In the observed population at the 1 -year time point, mean \pm SD 6 -min walking distance had changed by $51 \pm 74 \mathrm{~m}$ and WHO functional class had improved in $33 \%$, stabilised in $61 \%$ and worsened in $6 \%$ of the patients versus the PATENT-1 baseline.

Long-term riociguat was well tolerated in patients with pulmonary arterial hypertension, and led to sustained improvements in exercise capacity and functional capacity for up to 1 year.

@ERSpublications

Riociguat was well tolerated in patients with PAH, with sustained benefits in 6MWD and WHO FC for up to 1 year http://ow.ly/EskBj

For editorial comments see Eur Respir J 2015 45: 1211-1213 [DOI: 10.1183/09031936.00032715]

This article has supplementary material available from erj.ersjournals.com

Received: May 162014 | Accepted after revision: Nov 112014 | First published online: Jan 222015

Clinical trial: This study is registered at www.clinicaltrial.gov with identifier number NCT00863681.

Copyright @ERS 2015 


\section{Introduction}

Pulmonary arterial hypertension $(\mathrm{PAH})$ is a chronic, life-threatening disease, characterised by increased pulmonary vascular resistance (PVR) due to progressive vascular remodelling, which can ultimately lead to right heart failure and death $[1,2]$. Although several licensed therapies are available, PAH remains an incurable disease and there is a need for additional treatment options $[3,4]$.

Riociguat is a novel soluble guanylate cyclase (sGC) stimulator with a dual mode of action, sensitising sGC to endogenous nitric oxide by stabilising nitric oxide-sGC binding and directly stimulating sGC via a different binding site, independently of nitric oxide [5]. This results in increased production of cyclic GMP (cGMP) [5]. Riociguat is the first drug to demonstrate efficacy in two separate pulmonary hypertension $(\mathrm{PH})$ indications, $\mathrm{PAH}$ and chronic thromboembolic pulmonary hypertension (CTEPH) [6, 7], and has been approved for the treatment of both indications [3].

In the 12-week PATENT-1 study (Pulmonary Arterial Hypertension Soluble Guanylate Cyclase-Stimulator Trial 1), riociguat significantly improved 6-min walking distance (6MWD) in patients with PAH compared with placebo, with a least-squares mean difference of $36 \mathrm{~m}$ (95\% CI 20-52 m, p<0.0001) [6]. Riociguat also significantly improved several secondary end-points, including PVR $(\mathrm{p}<0.0001)$, N-terminal prohormone of brain natriuretic peptide (NT-proBNP) $(\mathrm{p}<0.001)$, World Health Organization (WHO) functional class $(\mathrm{p}=0.0033)$, time to clinical worsening $(\mathrm{p}=0.0046)$ and Borg dyspnoea score $(\mathrm{p}=0.002)$. Riociguat was generally well tolerated in PATENT-1; the most frequent serious adverse events (SAEs) were syncope, worsening $\mathrm{PH}$, chest pain and right ventricular failure [6].

Patients completing PATENT-1 were eligible to enter the PATENT-2, open-label, extension study, which assessed the long-term safety and efficacy of riociguat in patients with PAH. Here we report the results from an interim analysis of PATENT-2, where the majority of patients had received $\geqslant 1$ year of treatment.

\section{Methods}

Patients

The inclusion criteria for PATENT-1 have been published previously [6]. Patients were invited to participate in PATENT-2 after completing PATENT-1 without ongoing study drug-related SAEs. Patients who withdrew from PATENT-1, due to PH-related clinical worsening, were ineligible.

The study was carried out in accordance with Good Clinical Practice Guidelines and the Declaration of Helsinki. The study protocol was approved by the ethics committees of all participating centres and all patients gave their written, informed consent. The PATENT-1 study is registered at www.clinicaltrials.gov with identifier number NCT00810693.

\section{Study design}

PATENT-2 was a multicentre, open-label, single-group study, conducted in 97 of the 124 centres (across 27 of the 30 countries) that participated in PATENT-1. The study consisted of an 8-week, double-blind dose-adjustment phase, followed by an open-label study phase that will continue until all patients have transitioned to the commercially available drug.

During the open-label study phase, patients received an individually adjusted dose of riociguat up to a maximum of $2.5 \mathrm{mg}$ three times daily. Investigators could adjust the riociguat dose according to the patient's need, considering systolic blood pressure, side-effects and progression of underlying PAH. A detailed description of riociguat dosing during the PATENT study can be found in the supplementary appendix.

\section{Assessment}

The primary objective of the study was to assess the safety and tolerability of long-term riociguat treatment. Safety parameters included adverse events (AEs) and laboratory variables. Exploratory efficacy assessments included 6MWD, NT-proBNP, WHO functional class, time to clinical worsening, Borg dyspnoea score, EuroQol five-dimension component (EQ-5D) questionnaire and Living with Pulmonary Hypertension (LPH) questionnaire. Assessments took place at entry to PATENT-2, at weeks 2, 4, 6, 8 and 12, and every 3 months thereafter. All patients who stopped the study medication had a safety follow-up visit 30 days post discontinuation.

\section{Analysis}

All variables were analysed descriptively in this open-label, non-comparative study. Baseline refers to the start of the PATENT-1 study.

Support statement: This study was supported by Bayer HealthCare Pharmaceuticals (Berlin, Germany). Editorial assistance was provided by Adelphi Communications Ltd (Bollington, UK) sponsored by Bayer HealthCare Pharmaceuticals.

Conflict of interest: Disclosures can be found alongside the online version of this article at erj.ersjournals.com 
At week 12 of the PATENT-2 study, missing data were imputed according to last observation carried forward (LOCF), except in cases of death or clinical worsening without subsequent visit, where the following rules were used: $6 \mathrm{MWD}$, worst possible value $(0 \mathrm{~m})$; WHO functional class, worst possible score (IV) for cases of clinical worsening without subsequent visit and worst possible value plus one (V) for cases of death; Borg dyspnoea score, worst possible value (10); EQ-5D and LPH questionnaires, worst possible score. Worst possible values were not imputed for NT-proBNP.

In addition, the following exploratory missing data sensitivity analyses were performed at 1 year during the PATENT-2 study: LOCF, without worst case value imputation, for 6MWD; LOCF, with worst case plus one (V) imputation for cases of death, for WHO functional class; and mixed model for repeated measures (MMRM) analysis for 6MWD. The MMRM was applied with baseline value, visit, former treatment group, the interaction of visit and baseline and the interaction of visit and former treatment group, as fixed effects and an unstructured covariance matrix for the observations of one patient.

Rates of survival and clinical worsening at 1 year were estimated using a Kaplan-Meier analysis, in which patients were censored if they had not reached 1 year of treatment or if they had withdrawn without experiencing an event. In addition, worst case analyses were performed at 1 year for clinical worsening (assuming that a patient dropping out experienced clinical worsening immediately after drop-out), and survival (assuming that a patient dropping out died immediately after drop-out).

\section{Results}

Patients

Of the 405 patients who completed the PATENT-1 study, 396 (98\%) entered the PATENT-2 study (fig. 1). Patient characteristics were well balanced between groups at the PATENT-1 study baseline; $62 \%$ of patients had idiopathic PAH and 97\% were in WHO functional class II or III (table 1). At the March 2013 data cut-off, 324 patients $(82 \%)$ were receiving ongoing treatment and $84 \%$ had received $\geqslant 1$ year of treatment (fig. 1). Mean treatment duration was 95 weeks (median 91 weeks) and cumulative treatment exposure was 718 patient-years.

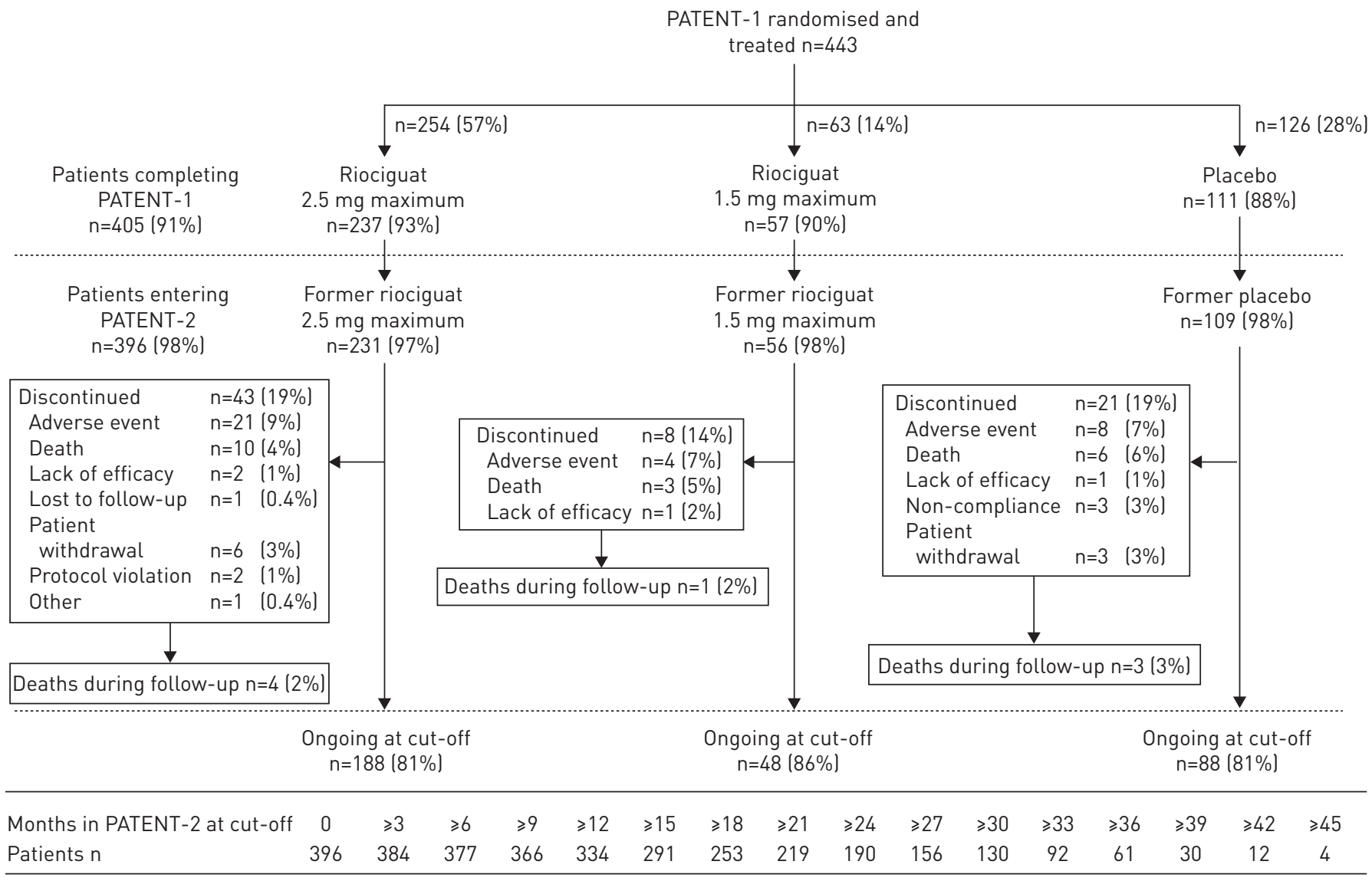

FIGURE 1 Patient disposition and number of patients at selected time points during the PATENT-2 study. 
TABLE 1 Patient characteristics at the PATENT-1 study baseline

\begin{tabular}{|c|c|c|c|c|}
\hline Characteristic & $\begin{array}{l}\text { Former riociguat } \\
2.5 \mathrm{mg} \text { maximum }\end{array}$ & $\begin{array}{l}\text { Former riociguat } \\
1.5 \mathrm{mg} \text { maximum }\end{array}$ & Former placebo & Total \\
\hline Patients n & 231 & 56 & 109 & 396 \\
\hline Female & $186(81)$ & $44(79)$ & $87(80)$ & $317(80)$ \\
\hline Treatment naïve & 114 (49) & $30(54)$ & $53(49)$ & $197(50)$ \\
\hline Pretreated & $117(51)$ & $26(46)$ & $56(51)$ & $199(50)$ \\
\hline Familial & $7(3)$ & $1(2)$ & $1(1)$ & $9(2)$ \\
\hline Connective tissue disease-associated $\mathrm{PAH}$ & $63(27)$ & $13(23)$ & $18(17)$ & $94(24)$ \\
\hline Congenital heart disease-associated $\mathrm{PAH}$ & $14(6)$ & 7 (13) & $12(11)$ & $33(8)$ \\
\hline Portal PH & $10(4)$ & 0 & $2(2)$ & $12(3)$ \\
\hline Anorexigen/amphetamine-associated $\mathrm{PAH}$ & $1(0.4)$ & 0 & $2(2)$ & $3(1)$ \\
\hline 6MWD m & $364 \pm 67$ & $359 \pm 68$ & $378 \pm 66$ & $367 \pm 67$ \\
\hline
\end{tabular}

Data are presented as mean $\pm \mathrm{SD}, \mathrm{n}(\%)$ or $\%$, unless otherwise stated. $\mathrm{PAH}$ : pulmonary arterial hypertension; $\mathrm{PH}$ : pulmonary hypertension; 6MWD: 6-min walking distance; WHO: World Health Organization. ${ }^{\#}$ : data does not add up to $100 \%$ due to rounding.

At the end of the 8-week, double-blind, dose-adjustment period, the majority of patients in the former riociguat $2.5 \mathrm{mg}$ maximum group, the former riociguat $1.5 \mathrm{mg}$ maximum group and the placebo group were receiving riociguat at a dose of $2.5 \mathrm{mg}$ three times daily $(79 \%, 91 \%$ and $77 \%$, respectively). This dosage was sustained at 1 year for the majority of the patients in the PATENT-2 study (86\%) (fig. S1). During the open-label phase of the PATENT-2 study, 49 patients received $\geqslant 1$ up-titration of the riociguat dose, and 41 patients received $\geqslant 1$ down-titration of the riociguat dose.

At the start of the PATENT-2 study, 199 (50\%) patients were receiving additional PAH-specific medication (all from the pretreated subgroup of the PATENT-1 study); 171 (43\%) were receiving endothelin receptor antagonists (ERAs), 25 (6\%) were receiving non-intravenous prostanoids and three (1\%) were receiving both ERAs and prostanoids. At 1 year of the PATENT-2 study, 164 (54\%) patients were receiving additional $\mathrm{PAH}$-specific medication (11\% of former therapy-naïve patients and $97 \%$ of former pretreated patients); 140 (46\%) were receiving ERAs, $11(4 \%)$ were receiving prostanoids and 13 (4\%) were receiving both ERAs and prostanoids.

Safety

The most common AEs found in the PATENT-2 study are shown in table 2. Hypotension was reported in $9 \%$ of patients and syncope in $7 \%$. Compared with the initial 12-week of the PATENT-1 study, lower exposure-adjusted rates per 100 patient-years were seen in the extension phase for the most frequent AEs and AEs of special interest (table S1).

Drug-related AEs were reported in $54 \%$ of patients; the most common were dizziness (9\%), headache (8\%) and dyspepsia (8\%). SAEs were reported in $52 \%$ of patients, and drug-related SAEs in $7 \%$. The most common drug-related SAEs included syncope (2\%) and worsening PAH (1\%). All cases were resolved, except for two cases of worsening PAH (one fatal and one not resolved).

During the PATENT-2 study, 25 (6\%) patients reported AEs and 10 (3\%) patients reported SAEs of haemoptysis/pulmonary haemorrhage. Of the reported SAEs in the PATENT-2 study, five were graded by study investigators as moderate and five were graded as severe. In two (1\%) patients, the cases were considered study-drug related by the investigators. One ( $0.3 \%)$ patient died (drug-related), one (0.3\%) patient required riociguat withdrawal (this patient subsequently died) and for one $(0.3 \%)$ patient the case was not resolved/resolving at the study cut-off point. In the remaining seven patients (2\%), haemoptysis/pulmonary haemorrhage had resolved or was resolving without the need for riociguat withdrawal or dose reduction.

In the PATENT-1 study, six (2\%) patients in the riociguat $2.5 \mathrm{mg}$ maximum group reported AEs and two (1\%) patients reported SAEs of haemoptysis/pulmonary haemorrhage. However, the exposure-adjusted rate of haemoptysis/pulmonary haemorrhage was lower in the PATENT-2 study compared with the 


\begin{tabular}{|c|c|c|c|c|}
\hline & $\begin{array}{l}\text { Former riociguat } \\
2.5 \mathrm{mg} \text { maximum }\end{array}$ & $\begin{array}{l}\text { Former riociguat } \\
1.5 \mathrm{mg} \text { maximum }\end{array}$ & Former placebo & Total \\
\hline Patients & 231 & 56 & 109 & 396 \\
\hline Any AE & $222(96)$ & 55 (98) & 107 (98) & 384 (97) \\
\hline \multicolumn{5}{|l|}{$\begin{array}{l}\text { Individual AEs in }>10 \% \\
\text { of patients }\end{array}$} \\
\hline Nasopharyngitis & $55(24)$ & $13(23)$ & $27(25)$ & 95 (24) \\
\hline Dizziness & $53(23)$ & $12(21)$ & $28(26)$ & 93 (23) \\
\hline Peripheral oedema & $50(22)$ & $14(25)$ & $25(23)$ & $89(22)$ \\
\hline Cough & $52(23)$ & $6(11)$ & $20(18)$ & $78(20)$ \\
\hline Diarrhoea & $32(14)$ & $11(20)$ & $27(25)$ & $70(18)$ \\
\hline Headache & $33(14)$ & $8(14)$ & $27(25)$ & $68(17)$ \\
\hline Nausea & $41(18)$ & $6(11)$ & $19(17)$ & $66(17)$ \\
\hline Vomiting & 30 (13) & $8(14)$ & $19(17)$ & $57(14)$ \\
\hline $\begin{array}{l}\text { Upper respiratory } \\
\text { tract infection }\end{array}$ & $29(13)$ & $8(14)$ & $17(16)$ & $54(14)$ \\
\hline Dyspnoea & $28(12)$ & $11(20)$ & $12(11)$ & $51(13)$ \\
\hline Dyspepsia & $29(13)$ & $8(14)$ & $10(9)$ & $47(12)$ \\
\hline Chest pain & $26(11)$ & $6(11)$ & $14(13)$ & $46(12)$ \\
\hline Epistaxis & $22(10)$ & $10(18)$ & $12(11)$ & $44(11)$ \\
\hline Drug-related AE & $123(53)$ & $26(46)$ & $66(61)$ & $215(54)$ \\
\hline Discontinued due to $\mathrm{AE}$ & $25(11)$ & $4(7)$ & $7(6)$ & $36(9)$ \\
\hline SAEs & $114(49)$ & $30(54)$ & $60(55)$ & $204(52)$ \\
\hline Discontinued due to SAE & $18(8)$ & $4(7)$ & $7(6)$ & $29(7)$ \\
\hline \multicolumn{5}{|l|}{$\begin{array}{l}\text { AEs of special interest } \\
\text { in }>5 \% \text { of patients }\end{array}$} \\
\hline Hypotension & $24(10)$ & $6(11)$ & $7(6)$ & $37(9)$ \\
\hline Syncope & $15(6)$ & $3(5)$ & $10(9)$ & $28(7)$ \\
\hline \multicolumn{5}{|l|}{ Other AEs of interest } \\
\hline $\begin{array}{l}\text { Haemoptysis/pulmonary } \\
\text { haemorrhage }\end{array}$ & $16(7)$ & $2(4)$ & $7(6)$ & $25(6)$ \\
\hline
\end{tabular}

Data are presented as $\mathrm{n}$ or $\mathrm{n}(\%)$. The mean treatment duration was 95 weeks. SAE: serious AE.

PATENT-1 study, due to the longer treatment duration of the PATENT-2 study. In the PATENT-2 study, the rate of haemoptysis/pulmonary haemorrhage AEs per 100 patient-years was 6.3 versus 9.9 in the riociguat groups and 11.1 in the placebo group of the PATENT-1 study. For SAEs, the exposure-adjusted rate of haemoptysis/pulmonary haemorrhage per 100 patient-years was 1.8 in PATENT-2 versus 4.3 in the riociguat groups of the PATENT-1 study (no SAEs of haemoptysis/pulmonary haemorrhage were reported in the placebo group of the PATENT-1 study).

In total, $61 \%$ of patients in the PATENT-2 study were receiving oral anticoagulants. However, no link has been identified between increased risk of respiratory tract bleeding events and antithrombotic therapy, treatment with vitamin $\mathrm{K}$ antagonists or the range of international normalised ratios. In addition, no link has been identified between respiratory tract bleeding and the dose of riociguat or the time after treatment initiation.

Overall, there were 27 deaths, three of which were considered study drug-related. These were due to haemoptysis/pulmonary haemorrhage and pneumonia; cardio-respiratory arrest and hypoxic-ischaemic encephalopathy; and worsening PAH.

\section{Exploratory analyses \\ 6MWD}

Improvements in 6MWD in the riociguat groups of the PATENT-1 study were sustained at week 12 and at 1 year of the PATENT-2 study, and patients in the placebo group of the PATENT-1 study showed comparable improvements with the former riociguat groups following transition to riociguat (fig. 2). At 1 year of the PATENT-2 study, 6MWD had changed by mean \pm SD $53 \pm 70 \mathrm{~m}$ for the former riociguat $2.5 \mathrm{mg}$ maximum group $(\mathrm{n}=192), 56 \pm 88 \mathrm{~m}$ in the former riociguat $1.5 \mathrm{mg}$ maximum group $(\mathrm{n}=50), 46 \pm 76 \mathrm{~m}$ in the former placebo group $(n=85)$ and $51 \pm 74 \mathrm{~m}$ in the overall population $(n=327)$ (fig. 2$)$. In the overall 


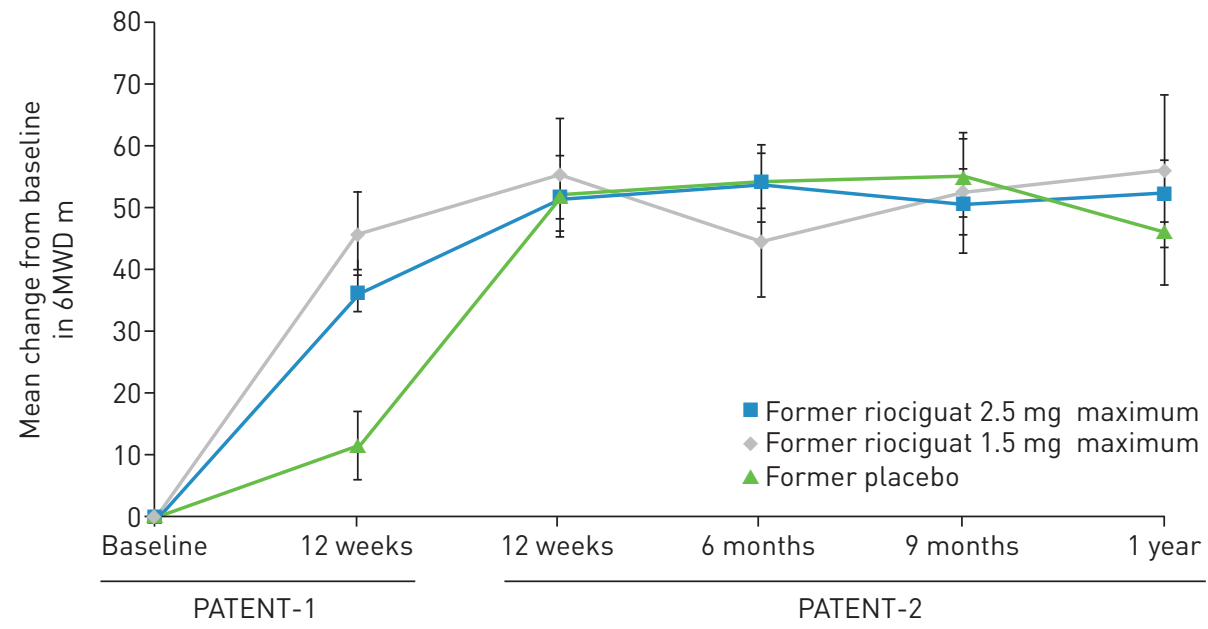

Mean 6MWD absolute values $\mathrm{m}$

Former riociguat

2.5 mg maximum

$1.5 \mathrm{mg}$ maximum

364

400

406

417

414

419

405

417

417

Former placebo

378

390

433

436

410

417

Patients $\mathrm{n}$

Former riociguat

$2.5 \mathrm{mg}$ maximum

228

218
54
103

211

436

426

Former placebo

109

108

103

54

$\begin{array}{cc}206 & 192 \\ 50 & 50 \\ 98 & 85\end{array}$

FIGURE 2 Mean change from baseline in 6-min walking distance (6MWD) in the PATENT-1 and PATENT-2 studies. Data are observed values and error bars represent standard error from the mean. ${ }^{\#}$ : Absolute value.

population, the absolute mean \pm SD 6 MWD was $419 \pm 97 \mathrm{~m}(\mathrm{n}=327)$ at 1 year, compared with $367 \pm 67 \mathrm{~m}$ $(\mathrm{n}=396)$ at baseline.

Missing data sensitivity analyses, using different imputation methods, showed slightly lower improvements in 6MWD compared with observed values (table S2). This was due to patients who dropped out tending to have a lower $6 \mathrm{MWD}$ prior to drop-out. However, the overall interpretation of the study results was not affected.

Riociguat increased the proportion of patients achieving a $6 \mathrm{MWD} \geqslant 380 \mathrm{~m}$ in the PATENT-1 study, and this persisted for up to 1 year in the PATENT-2 study. The proportion of former placebo patients achieving a $6 \mathrm{MWD} \geqslant 380 \mathrm{~m}$ showed a similar increase following transition to riociguat in the PATENT-2 study (fig. S2).

\section{NT-proBNP}

The decreases in NT-proBNP in the riociguat groups of the PATENT-1 study were sustained for up to 1 year in the PATENT-2 study, with former placebo patients showing a similar decrease following transition to riociguat (table 3 ).

\section{WHO functional class}

At 1 year, WHO functional class had improved, stabilised or worsened in: $36 \%, 57 \%$ and $7 \%$ of patients, respectively, in the former riociguat $2.5 \mathrm{mg}$ maximum group ( $\mathrm{n}=199) ; 31 \%, 67 \%$ and $2 \%$ of patients in the former riociguat $1.5 \mathrm{mg}$ maximum group $(n=51) ; 26 \%, 66 \%$ and $8 \%$ of patients in the former placebo group ( $n=89)$; and $33 \%, 61 \%$ and $6 \%$ of patients in the overall population $(n=339)$ (fig. 3). The proportion of patients in WHO functional classes I, II, III and IV in the overall population was $8 \%, 61 \%, 28 \%$ and $2 \%$ $(\mathrm{n}=339)$ at 1 year, compared with $3 \%, 43 \%, 54 \%$ and $1 \%(n=395)$ at baseline.

Similar to $6 \mathrm{MWD}$, missing data sensitivity analyses showed slightly reduced improvements in WHO functional class compared with observed values (table S2), but the overall interpretation of study results was not affected. 
TABLE 3 Change from the PATENT-1 study baseline during the PATENT-1 study and the PATENT-2 study

\begin{tabular}{|c|c|c|c|c|c|c|c|c|c|c|}
\hline & \multicolumn{3}{|c|}{ Former riociguat $2.5 \mathrm{mg}$ maximum } & \multicolumn{3}{|c|}{ Former riociguat $1.5 \mathrm{mg}$ maximum } & \multicolumn{3}{|c|}{ Placebo } & \multirow{3}{*}{$\begin{array}{c}\text { Total } \\
\text { population } \\
\text { PATENT-2 } \\
1 \text { year }\end{array}$} \\
\hline & \multirow{2}{*}{$\begin{array}{c}\text { PATENT-1 } \\
\text { week } 12\end{array}$} & \multicolumn{2}{|c|}{ PATENT-2 } & \multirow{2}{*}{$\begin{array}{l}\text { PATENT-1 } \\
\text { week } 12\end{array}$} & \multicolumn{2}{|c|}{ PATENT-2 } & \multirow{2}{*}{$\begin{array}{l}\text { PATENT-1 } \\
\text { week } 12\end{array}$} & \multicolumn{2}{|c|}{ PATENT-2 } & \\
\hline & & Week 12 & 1 year & & Week 12 & 1 year & & Week 12 & 1 year & \\
\hline \multicolumn{11}{|l|}{ NT-proBNP } \\
\hline Observed values $\mathrm{pg} \mathrm{mL}^{-1}$ & $-338 \pm 1031$ & $-322 \pm 1206$ & $-291 \pm 1612$ & $-447 \pm 954$ & $-520 \pm 944$ & $-235 \pm 1214$ & $134 \pm 809$ & $-410 \pm 1023$ & $-294 \pm 1945$ & $-284 \pm 1653$ \\
\hline Patients & 207 & 201 & 177 & 46 & 46 & 44 & 95 & 93 & 80 & 301 \\
\hline \multicolumn{11}{|l|}{ Borg dyspnoea score } \\
\hline Observed values & $-0.55 \pm 1.52$ & $-0.58 \pm 1.84$ & $-0.52 \pm 1.98$ & $-0.43 \pm 1.19$ & $-0.52 \pm 1.64$ & $-0.18 \pm 1.58$ & $-0.15 \pm 1.88$ & $-0.54 \pm 1.90$ & $-0.45 \pm 2.06$ & $-0.45 \pm 1.94$ \\
\hline Patients & 228 & 218 & 192 & 55 & 54 & 49 & 108 & 102 & 84 & 325 \\
\hline \multicolumn{11}{|l|}{ EQ-5D score } \\
\hline Observed values & $0.05 \pm 0.21$ & $0.06 \pm 0.22$ & $0.06 \pm 0.24$ & $0.10 \pm 0.26$ & $0.15 \pm 0.24$ & $0.13 \pm 0.24$ & $0.02 \pm 0.22$ & $0.03 \pm 0.24$ & $0.07 \pm 0.20$ & $0.07 \pm 0.23$ \\
\hline Patients & 227 & 212 & 193 & 55 & 52 & 50 & 106 & 102 & 83 & 326 \\
\hline \multicolumn{11}{|l|}{ LPH score } \\
\hline Observed values & $-7.6 \pm 16.8$ & $-11.0 \pm 18.9$ & & $-11.8 \pm 16.1$ & $-14.3 \pm 18.9$ & & $-2.7 \pm 15.1$ & $-2.1 \pm 15.7$ & & \\
\hline Patients & 224 & $209^{\#}$ & & 55 & $54^{\#}$ & & 105 & $93^{\#}$ & & \\
\hline
\end{tabular}

Data are presented as mean \pm SD or n. NT-proBNP: N-terminal prohormone of brain natriuretic peptide; EQ-5D: Euro Qol Group 5-Dimension Self-Report Questionnaire. ${ }^{\#}$ : Week 8 data shown for Living with Pulmonary Hypertension (LPH) score. 


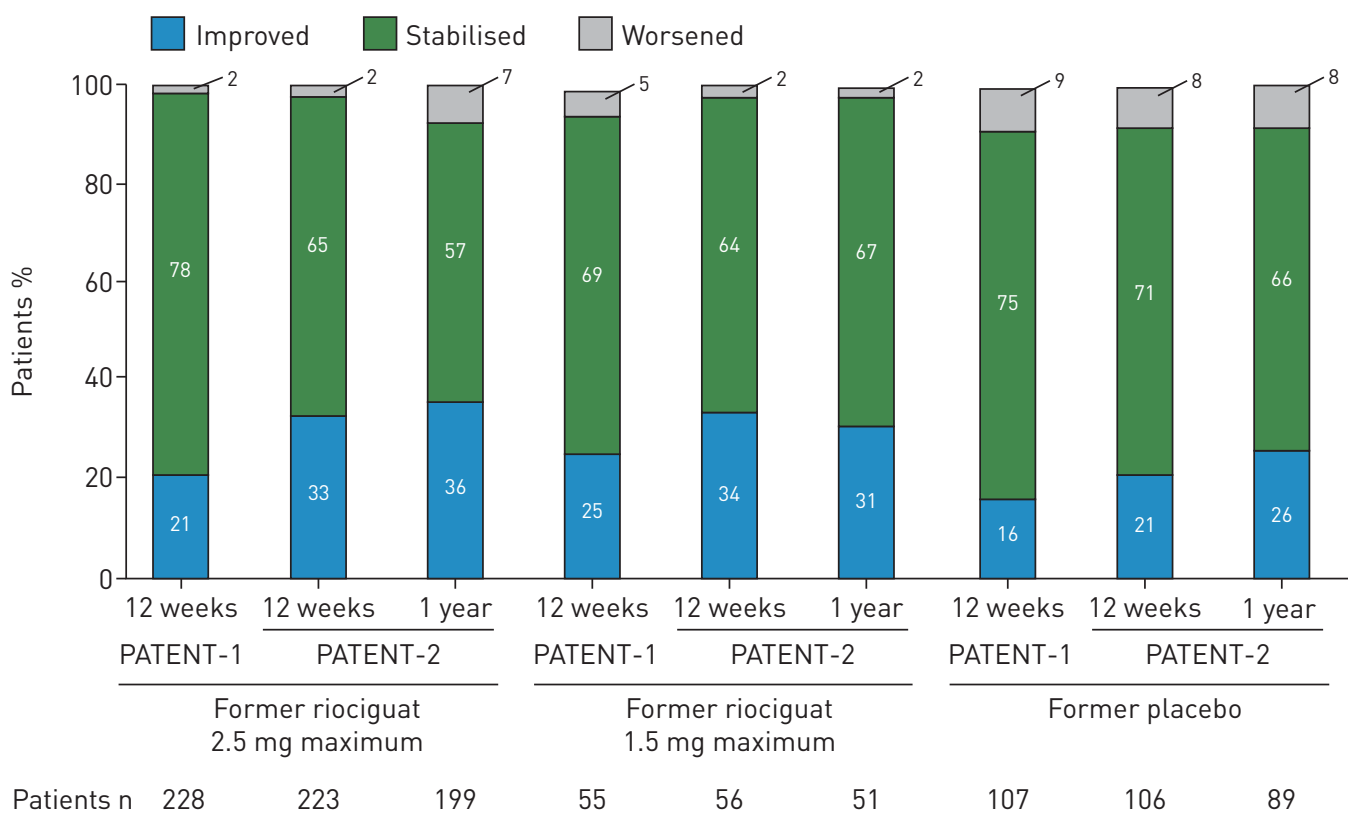

FIGURE 3 The proportion of patients in whom World Health Organization functional class was improved, stabilised or worsened in the former riociguat $2.5 \mathrm{mg}$ maximum patient group, the former riociguat $1.5 \mathrm{mg}$ maximum patient group and the former placebo patient group. Data are observed values. Percentages may not add up to $100 \%$ due to rounding.

\section{Survival and clinical worsening}

Overall, 21\% of patients experienced a clinical worsening event during the PATENT-2 study (table 4). The estimated rate of clinical worsening-free survival at 1 year was $88 \%$ (95\% CI, 84-91\%) (fig. 4a). The estimated survival rate at 1 year was 97\% (95\% CI 94-98\%) (fig. 4b). However, these analyses assume that patients dropping out have the same event rate as those who continue, which may lead to positive bias if the event rate after drop out is higher. We therefore performed worst-case sensitivity analyses for survival and clinical worsening, in which patients who dropped out were assumed to have died or experienced clinical worsening. Using these analyses, the rate of clinical worsening-free survival at 1 year was $84 \%$ (95\% CI $80-87 \%$ ) and the rate of survival at 1 year was 90\% (95\% CI $87-93 \%$ ).

Survival was similar in patients with idiopathic/familial PAH and PAH associated with connective tissue disease (fig. S3), with estimated 1-year survival rates of 97\% (95\% CI 94-99\%) and 97\% (95\% CI 90-99\%), respectively. Survival was also similar between treatment-naïve patients and patients pretreated with ERAs or prostanoids (fig. S4), with estimated 1-year survival rates of $97 \%$ (95\% CI 93-99\%) in both subgroups.

\section{TABLE 4 Clinical worsening events during PATENT-2}

\begin{tabular}{cc}
\multicolumn{2}{c}{ Former riociguat } \\
\hline $2.5 \mathrm{mg}$ & $1.5 \mathrm{mg}$ \\
maximum & maximum
\end{tabular}

Former placebo Total

\begin{tabular}{lcccc}
\hline Patients & 231 & 56 & 109 & 396 \\
Patients with clinical worsening $^{\#}$ & $49(21)$ & $11(20)$ & $24(22)$ & $84(21)$ \\
Heart/lung transplantation & $1(0.4)$ & $1(2)$ & 0 & $2(1)$ \\
Hospitalisation due to PH & $25(11)$ & $5(9)$ & $11(10)$ & $41(10)$ \\
Start of new PH treatment & $34(15)$ & $9(16)$ & $17(16)$ & $60(15)$ \\
Decrease in 6MWD due to PH & $6(3)$ & $1(2)$ & $3(3)$ & $10(3)$ \\
Persistent worsening in WHO FC due to PH & $4(2)$ & 0 & $1(1)$ & $5(1)$ \\
Died & $14(6)$ & $4(7)$ & $9(8)$ & $27(7)$
\end{tabular}

Data are presented as $\mathrm{n}$ or $\mathrm{n}(\%)$. $\mathrm{PH}$ : pulmonary hypertension; 6MWD: 6-min walking distance; WHO: World Health Organization; FC: functional class. ${ }^{\#}$ : one patient can experience more than one type of event. The mean treatment duration was 95 weeks. 

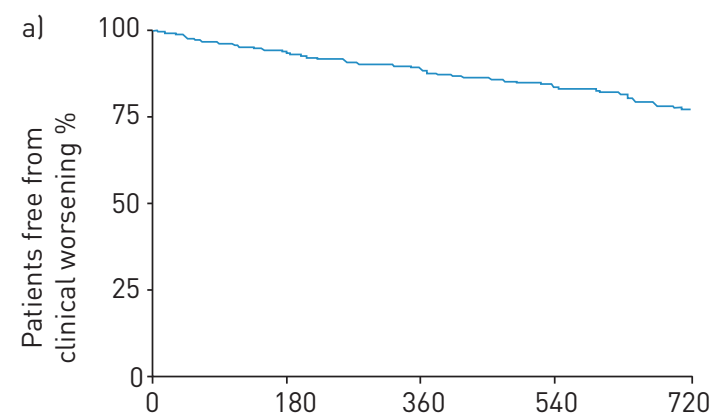

Time from start of extension study treatment days

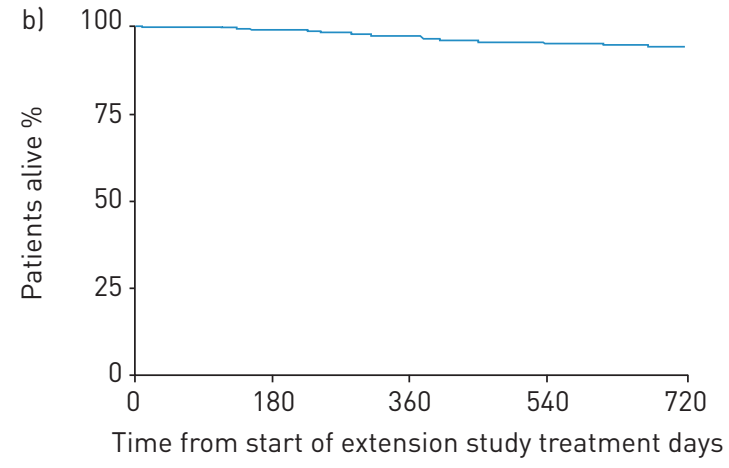

Time from start of extension study treatment days

$\begin{array}{lccccc}\begin{array}{l}\text { Patients who reached } \\ \text { time point without } \\ \text { clinical worsening n }\end{array} & 396 & 360 & 288 & 209 & 145 \\ \begin{array}{l}\text { Patients with clinical } \\ \text { worsening } n\end{array} & 0 & 26 & 43 & 60 & 73\end{array}$

\begin{abstract}
Patients alive at time point $n$
\end{abstract}

Deaths $\mathrm{n}$
396

0
377

4

$\begin{array}{lll}310 & 234 & 168 \\ 12 & 18 & 21\end{array}$

FIGURE 4 Kaplan-Meier plots for a) clinical worsening and b) survival in the overall population during the PATENT-2 study. At 1 year, the estimated rate of clinical worsening-free survival was $88 \%$ (95\% CI 84-91\%) and the estimated survival rate was $97 \%$ (95\% CI 94-98\%). Using a worst-case analysis for clinical worsening, where patients who dropped out were assumed to have experienced clinical worsening, the rate of clinical worsening-free survival at 1 year was $84 \%$ ( $95 \%$ CI $80-87 \%)$. Using a worst-case analysis for survival, where patients who dropped out were assumed to have died, the rate of survival at 1 year was $90 \%$ (95\% CI 87-93\%).

\section{Quality of life}

Improvements in EQ-5D and Borg dyspnoea scores in patients receiving riociguat in the PATENT-1 study were sustained in the overall PATENT-2 study population for up to 1 year (table 3). Improvements in LPH score in the riociguat $2.5 \mathrm{mg}$ maximum and the $1.5 \mathrm{mg}$ maximum groups in the PATENT-1 study continued through to week 8 of the PATENT-2 study (LPH was not measured beyond week 8 during PATENT-2). However, a minimal change was observed in the former placebo group at week 8 during the PATENT-2 study (table 3).

\section{Discussion}

Data generated from the PATENT-2 study support the findings from the PATENT-1 study, i.e. that riociguat is a well-tolerated and effective treatment for patients with symptomatic PAH, either for treatment-naïve patients or patients who are already being treated with an ERA or a prostanoid. The AE profile of riociguat in the PATENT-2 study was similar to that seen in the PATENT-1 study [6], with no new safety signals identified. The good tolerability of riociguat was underlined by the fact that the majority of patients were receiving the maximum $2.5 \mathrm{mg}$ three times daily dose of riociguat at 1 year.

Syncope is a critical AE observed in patients with $\mathrm{PAH}$, and may be increased by $\mathrm{PAH}$-specific therapy [8-11]. The rate of syncope in the PATENT-2 study was 5.9 cases per 100 patient-years (7\% of patients), slightly lower than the rate observed in the riociguat $2.5 \mathrm{mg}$ maximum group in the PATENT-1 study (8.8 cases per 100 patient-years ( $1 \%$ of patients)). Of note, the rate of syncope in the PATENT-1 study was higher in the placebo group compared with the riociguat $2.5 \mathrm{mg}$ maximum group (4\% versus $1 \%$ ) [6]. The incidence of syncope in the PATENT-2 study is comparable to that observed in the long-term studies in patients with PAH with sildenafil (11\%) [11] and treprostinil (4\%) [9].

Haemoptysis and pulmonary haemorrhage are known complications of PAH [12, 13]. The rate of haemoptysis and pulmonary haemorrhage SAEs in the PATENT-2 study was 1.8 cases per 100 patient-years (3\% of patients) compared with 4.3 cases per 100 patient-years in the riociguat groups of the PATENT-1 study (1\% of patients). The potentially increased risk of pulmonary bleeding with riociguat in some patients is reflected as a warning in the local prescribing information (summary of product characteristics) and should be considered as drug-related. However, the risk of haemoptysis and pulmonary haemorrhage may be influenced by other factors, such as age, severity of disease, deterioration in pulmonary haemodynamics and concomitant treatment with anticoagulants $[12,14]$. The mechanism of how riociguat could cause haemoptysis and pulmonary haemorrhage is unclear. One hypothesis is that the observation may be related to the vasodilatory effects of riociguat on the bronchial arterial circulation, which is hypertrophied and associated with angiogenesis in the systemic circulation i.e. bronchial arteries, in $\mathrm{PH}[13,15]$, increasing the flow and favouring haemoptysis. 
The improvements in 6MWD and WHO functional class, observed in the riociguat groups in the 12-week PATENT-1 study were sustained for up to 1 year in the PATENT-2 study. At week 12 of the PATENT-2 study, 6MWD had increased by $52 \mathrm{~m}$ in the former riociguat $2.5 \mathrm{mg}$ maximum group (after 6 months of active treatment). In patients reaching 1 year of treatment, an increase in 6MWD of $51 \mathrm{~m}$ was observed, with $33 \%$ and $61 \%$ of patients, showing improvement and stabilisation, respectively, in WHO functional class. Importantly, in the former placebo group, improvements in 6MWD and WHO functional class approached that of the former riociguat groups after 12 weeks and 1 year of the PATENT-2 study. The improvements in 6MWD and WHO functional class were consistent using a variety of imputation methods for missing data.

The estimated survival rate at 1 year for the PATENT-2 study was $97 \%$, and the incidences of clinical worsening and hospitalisation, due to $\mathrm{PAH}$, were relatively low $(21 \%$ and $10 \%$, respectively, median treatment duration of 91 weeks), supporting the long-term efficacy of riociguat in patients with PAH. Using worst-case sensitivity analyses, in which patients who dropped out were assumed to have died or experienced clinical worsening, the 1-year rates of survival and clinical-worsening free survival were $90 \%$ and $84 \%$, respectively.

Other PAH therapies have shown efficacy in long-term extension studies [8, 9, 11, 16-18]. The study closest to that of the PATENT-2 study, in terms of study design and population, may be the PHIRST-2 study (Pulmonary Arterial Hypertension and Response to Tadalafil), in which patients with PAH received open-label tadalafil (20 mg or $40 \mathrm{mg}$ ) for up to 1 year [17]. More recently, results were reported from the phase III SERAPHIN study (Study with an Endothelin Receptor Antagonist in Pulmonary Arterial Hypertension to Improve Clinical Outcome), a long-term event-driven study investigating macitentan for $\mathrm{PAH}$ [19]. However, due to differences in durations, end-points and study populations, inter-study comparisons are difficult.

The PATENT-2 study has several limitations that are common to all open-label long-term extension studies. Although there was no placebo-controlled group in the present study, long-term administration of placebo to patients with a progressive disease, such as $\mathrm{PAH}$, may lead to clinical deterioration. An open-label follow-up of an initial randomised study provides additional safety data and reinforces efficacy findings. The lack of a placebo group and the fact that approximately $50 \%$ of patients were receiving concomitant treatment with additional PAH-targeted therapies, also mean that it is impossible to unequivocally attribute all of the efficacy and safety findings to riociguat. Nevertheless, while the relatively low rate of add-on therapy in the treatment-naive subgroup after 1 year (11\%) supports the long-term efficacy of riociguat, this may, in part, be due to the lack of access to PAH-specific medication at some centres.

A further limitation is that patient withdrawal may have led to bias towards patients who responded well to riociguat treatment at later time points. This could have resulted in an overestimation of improvements in efficacy parameters at 1 year. To address this, we performed a number of sensitivity analyses for 6MWD and the WHO functional class. These analyses resulted in lower but comparable estimates of efficacy.

In addition, the frequency of visits during the open-label phase of the PATENT-2 study (every 3 months) was lower than the frequency of visits in the PATENT-1 study (every 2 weeks). This may have resulted in a lower level of estimation for the frequency of non-serious AEs during the PATENT-2 study compared with the PATENT-1 study, due to potential recall bias.

In conclusion, long-term treatment with riociguat was well tolerated in patients with PAH. As in the PATENT-1 study, cases of haemoptysis/pulmonary haemorrhage were observed in the PATENT-2 long-term extension study. Improvements in exercise capacity and functional capacity were maintained for up to 1 year of treatment, with a survival rate of $97 \%$ and a rate of clinical worsening-free survival of $88 \%$ at 1 year (worst case analyses were $90 \%$ and $84 \%$, respectively). These results support that riociguat is an effective long-term treatment for $\mathrm{PAH}$, both as a monotherapy and in combination with ERAs and prostanoids.

\section{References}

1 Galiè N, Hoeper MM, Humbert M, et al. Guidelines for the diagnosis and treatment of pulmonary hypertension: the Task force for the diagnosis and treatment of pulmonary hypertension of the European Society of Cardiology (ESC) and the European Respiratory Society (ERS), endorsed by the International Society of Heart and Lung Transplantation (ISHLT). Eur Heart J 2009; 30: 2493-2537.

2 McLaughlin VV, Archer SL, Badesch DB, et al. ACCF/AHA 2009 expert consensus document: ACCF/AHA 2009 expert consensus document on pulmonary hypertension. Circulation 2009; 119: 2250-2294.

3 Galiè N, Corris PA, Frost A, et al. Updated treatment algorithm of pulmonary arterial hypertension. J Am Coll Cardiol 2013; 62; Suppl., D60-D72.

4 O'Connell C, O'Callaghan DS, Humbert M. Novel medical therapies for pulmonary arterial hypertension. Clin Chest Med 2013; 34: 867-880.

5 Grimminger F, Weimann G, Frey R, et al. First acute haemodynamic study of soluble guanylate cyclase stimulator riociguat in pulmonary hypertension. Eur Respir J 2009; 33: 785-792. 
6 Ghofrani HA, Galiè N, Grimminger F, et al. Riociguat for the treatment of pulmonary arterial hypertension. N Engl J Med 2013; 369: 330-340.

7 Ghofrani HA, D'Armini AM, Grimminger F, et al. Riociguat for the treatment of chronic thromboembolic pulmonary hypertension. N Engl J Med 2013; 369: 319-329.

8 Barst RJ, McGoon M, McLaughlin V, et al. Beraprost therapy for pulmonary arterial hypertension. J Am Coll Cardiol 2003; 41: 2119-2125.

9 Barst RJ, Galie N, Naeije R, et al. Long-term outcome in pulmonary arterial hypertension patients treated with subcutaneous treprostinil. Eur Respir J 2006; 28: 1195-1203.

10 Olschewski H, Simonneau G, Galiè N, et al. Inhaled iloprost for severe pulmonary hypertension. $N$ Engl J Med 2002; 347: 322-329.

11 Rubin LJ, Badesch DB, Fleming TR, et al. Long-term treatment with sildenafil citrate in pulmonary arterial hypertension: the SUPER-2 study. Chest 2011; 140: 1274-1283.

12 Tio D, Leter E, Boerrigter B, et al. Risk factors for hemoptysis in idiopathic and hereditary pulmonary arterial hypertension. PLoS One 2013; 8: e78132.

13 Zylkowska J, Kurzyna M, Pietura R, et al. Recurrent hemoptysis: an emerging life-threatening complication in idiopathic pulmonary arterial hypertension. Chest 2011; 139: 690-693.

14 Henkens IR, Hazenoot T, Boonstra A, et al. Major bleeding with vitamin $\mathrm{K}$ antagonist anticoagulants in pulmonary hypertension. Eur Respir J 2013; 41: 872-878.

15 Fadel E, Wijtenburg E, Michel R, et al. Regression of the systemic vasculature to the lung after removal of pulmonary artery obstruction. Am J Respir Crit Care Med 2006; 173: 345-349.

16 Benza RL, Seeger W, McLaughlin VV, et al. Long-term effects of inhaled treprostinil in patients with pulmonary arterial hypertension: the treprostinil sodium inhalation used in the management of pulmonary arterial hypertension (TRIUMPH) study open-label extension. J Heart Lung Transplant 2011; 30: 1327-1333.

17 Oudiz RJ, Brundage $\mathrm{BH}$, Galie N, et al. Tadalafil for the treatment of pulmonary arterial hypertension: a double-blind 52-week uncontrolled extension study. J Am Coll Cardiol 2012; 60: 768-774.

18 Sitbon O, Badesch DB, Channick RN, et al. Effects of the dual endothelin receptor antagonist bosentan in patients with pulmonary arterial hypertension: a 1-year follow-up study. Chest 2003; 124: 247-254.

19 Pulido T, Adzerikho I, Channick RN, et al. Macitentan and morbidity and mortality in pulmonary arterial hypertension. N Engl J Med 2013; 369: 809-818. 